Guocai Wang, Dong Liu, Xifeng Wang

\title{
Effects of Perceived Organizational Support and Guanxi on Salesperson Performance: The Mediation of Customer Need Knowledge
}

\author{
(C) Higher Education Press and Springer-Verlag 2011
}

\begin{abstract}
Based on data from car dealers in China, this study examines the impacts of perceived organizational support (POS) and guanxi on personal performance and the mediating role of customer need knowledge (CNK). Results indicate that salespersons' POS and guanxi with customers have a positively influence on their CNK and job performance; their CNK is also positively related to job performance. Meanwhile, CNK acts as a full mediator between salespersons' POS and their job performance, and as a partial mediator between salespersons' guanxi with clients and their job performance.
\end{abstract}

Keywords perceived organizational support (POS), guanxi, customer need knowledge (CNK), salesperson performance

\section{Introduction}

Market-orientation emphasizes that companies should generate, disseminate and respond to information about customer needs (e.g., Kohli and Jaworski, 1990; Sinkula, 1994). Therefore, an accurate identification of customer needs is a prerequisite for successful market orientation. Accordingly, a key question to

Received December 13, 2010

Guocai Wang

Marketing Department, School of Business, Nanjing University, Nanjing 210093, China

E-mail: wgcxfeng@nju.edu.cn

Dong Liu $(\bowtie)$

Marketing department, School of Business, Nanjing University, Nanjing 210093, China

E-mail: flow123flow@163.com

Xifeng Wang

School of Economics and Management, Nanjing University of Technology, Nanjing 210009, China

E-mail: wgcxfeng@nju.edu.cn 
managers is how to identify customer needs accurately. Previous literature has advocated that frontline employees act as a crucial source for perceiving customer needs, thanks to their direct customer interaction (Liao and Chuang, 2004; Gwinner et al., 2005). For example, Homburg, Wieseke and Bornemann (2009) employed customer need knowledge (CNK) to measure the accuracy of frontline employees' perceptions of customer needs. CNK is defined as the extent to which a customer's ranking of his or her shopping-related needs is consistent with the ranking assumed by a frontline employee for this customer (Homburg, Wieseke and Bornemann, 2009).

According to the service marketing triangle (Zeithaml and Bitner, 1996), frontline employees not only interact with customers but also are influenced by their companies. The triangle outlines the interrelationship between three key constituents: customers, employees, and companies. The link between a company and its employees concentrates on enabling employees to deliver satisfying services by appropriate resources such as training and incentives. The relationship between employees and customers is represented by interactive marketing - where promises made to customer become reality (Bitner, Brown and Meuter, 2000). Morrison (1996) highlighted the notion that the employee-organization relationship has implications for employees' service-oriented attitudes and behaviors. Internal marketing theorists have argued that it is impossible for businesses to provide better service for external customers than that they provide to their employees or internal customers (George, 1990). Only after effective internal exchanges have occurred can successful external exchanges between employees and customers take place (Bell and Menguc, 2002). Therefore, the internal exchanges between employees and an organization can affect external exchanges between employees and customers.

In the social exchange theory, exchanges between employees and their company are considered perceived organizational support (POS). POS is defined as the extent to which employees perceive that their contributions are valued by their organization and that the organization cares about their well-being (Eisenberger, Fasolo and Davis-LaMastro, 1990). On the other hand, Davies (1995) noted that guanxi is a special type of relationship that bonds the exchange partners through reciprocal obligations to obtain resources through a continual cooperation and exchange of favors. Therefore, we can use guanxi to reflect exchanges between an employee and customers. Accordingly, an interesting question arises: How do POS and guanxi affect CNK?

This paper tries to answer the above question by making the following contributions. First, pervious literature has examined many consequences of POS, such as organizational citizenship behavior (e.g., Moorman, Blakely and Niehoff, 1998), organization commitment (e.g., Stinglhamber and Vandenberghe, 2003; Bishop, Scott and Goldsby, 2005), turnover (e.g., Allen, Shore and Griffeth, 2003; 
Hochwarter, Kacmar, Perrewe and Johnson, 2003), performance (e.g., Kraimer, Wayne and Jaworski, 2001; Chong, White and Prybutok, 2001). However, previous research mainly focused on human resource management, little has explored the impact of POS on employees' perception of customers' needs. The aim of the current study is therefore to test the link between POS and CNK. Second, whereas a company and its employees and customers have been considered the three main bodies in the exchanges, most existing studies concentrate on either the exchange between employees and their company or employee-customer interaction. Little research has integrated both to examine their joint impact on performance. Our paper combines POS and guanxi to examine their influence on employee performance. Third, the accuracy of frontline employees' perceptions of customer needs has been assumed to be a key element of the marketing concept (Homburg et al., 2009). However, it has received little attention in empirical research. We aim to examine the mediating role played by CNK in linking the two exchanges and employees' performance. The conceptual model of this article is shown in Fig. 1.

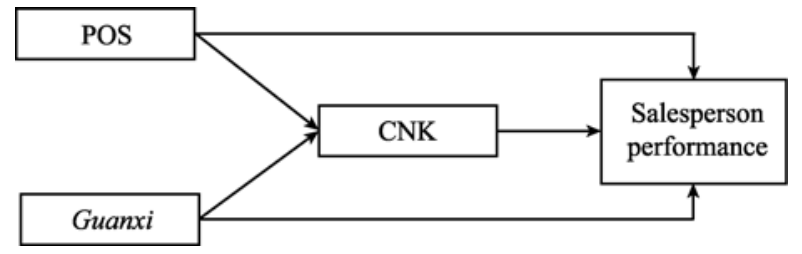

Fig. 1 The Conceptual Model

\section{Theory and Hypotheses}

\subsection{Perceived Organizational Support and Customer Need Knowledge}

According to Blau's (1964) social exchange theory, employees will trade their efforts for the promise of material and personal rewards that the organization may offer in the future (Stamper and Johlke, 2003). Those rewards include time off for education, developmental experiences and promotions (Wayne et al., 1997). Employees with high level of POS not only feel that they ought to be committed to their organization, but also feel an obligation to repay the promise by engaging in behaviors to support organizational goal (Wayne et al., 1997). Eisenberger et al. (1986) suggested that an employee's perception of how an organization values him or her may be vital for determining if any attitudes or behaviors benefiting the organization emerge from the social exchange relationship. What will frontline employees with a high level of POS behavior do to repay their organizations? As frontline employees often spend much of their working time directly interacting with customers and addressing customers' 
highly variable, complex and distinctive needs, they will, as a return, probably work hard to provide a high quality service and promote sales.

The high quality of service and amount of sales entail accurate perceptions of customer needs and customer satisfaction. To satisfy customer needs, frontline employees must acquire knowledge about these needs (Goff et al., 1997). Organization plays a crucial role in knowledge acquirement by providing intangible investment. For instance, an organization can offer training in terms of customer-oriented interaction behaviors to emphasize the conversation skills necessary for gathering accurate information about customer needs and for making right decisions which can satisfy customer needs (Homburg et al., 2009). Wayne et al. (1997) found a positive association between training and employee POS. Johlke et al. (2002) stressed that frontline employees (such as salespersons, technicians, and mechanics) rely upon training provided by the firm to continuously develop their skills, product and customer knowledge. In this vein, salespersons' ability to accurately identify customer needs can be improved. Namely, POS can enhance the CNK of salesperson.

Eisenberger et al. reported that POS is positively associated with job performance (Eisenberger et al., 1986, 1990). This argument is consistent with the findings of Kraimer, Wayne and Jaworski (2001) and Chong, White and Prybutok (2001). Notwithstanding, a paucity of research has explored the impact of POS on the perception of customer needs.

Based on the discussion above, we hypothesize,

H1 POS is positively related to the CNK of salespersons.

H2 POS is positively related to salesperson performance.

H3 CNK acts as a mediator between POS and salesperson performance.

\subsection{Guanxi and Customer Need Knowledge}

CNK requires frontline employees to identify customer needs accurately. Living in Chinese society, everyone is aware of the importance of guanxi in everyday life. Guanxi can be defined at different levels and from different perspectives. Guanxi is a special type of relationship that bonds the exchange partners through reciprocal obligations to obtain resources through a continual cooperation and exchange of favors (Davies, 1995). Wang (2007) pointed out that guanxi is a special type of relationship, relationship does not necessarily mean guanxi. Luo and Chen (1997) conceptualized guanxi as drawing on connections or networks to secure favor in personal or business relationship. Wong and Tjosvold (2010) pointed out that a high level of guanxi is by nature a quality, close relationship characterized by bestowing and receiving of benefits from each other. However, for the purpose of our study, we adopted the definition of guanxi given by Chen 
and Chen (2004), which regards guanxi as an informal, particularistic personal connection between two individuals bounded by an implicit psychological contract to follow the social norms such as maintaining a long-term relationship, mutual commitment, loyalty and obligation.

For frontline employees, guanxi plays a crucial role while they start working. Gwinner et al. (1998) indicated that keeping employees with customers for longer periods of time facilitates the accurate identification of customer needs and thus enables the realization of customization benefits. Moreover, frontline employees have difficulty in identifying prospective customers. However, frontline employees possessing a high level of guanxi with customers can understand and recognize the right customers (Luo and Chen, 1997). Their prospective customers include not only friends, relatives, but also those who are recommended by their relatives and friends. Based on a high level of guanxi, frontline employees can acquire more information about a customer's needs. In addition, customers can express what they need to frontline employees. During their interactions, frontline employees will offer more specific service and suitable product to the customer, thus improving customer value.

Ramasamy et al. (2006) empirically proved that the communication and trust between people have a significantly positive impact on knowledge transfer. By investigating in the health care industry, Geddie et al. (2002) argued that guanxi help improve patient satisfaction. After a comparison between salespersons in China and the USA, Abramson and Ai (1997) claimed that the better guanxi between a seller and a buyer, the lower uncertainty and the more successful the business.

In light of the analysis above, we hypothesize:

H4 Guanxi is positively related to the CNK of salesperson.

H5 Guanxi is positively related to salesperson performance.

H6 CNK acts as a mediator for the relationship between guanxi and salesperson performance.

\subsection{Customer Need Knowledge and Personal Performance}

CNK reflects the accuracy of frontline employees' perception of customer needs. As a typical type of frontline employees, salespersons with high level of CNK can know what products customers need. For example, knowing brand is of more importance to a customer than price, a salesperson will be able to sell more expensive product easily (Sharma and Lambert, 1994). Homburg (2009) found that the CNK of a frontline employee has a positive effect on the customer's purchase intention.

Therefore, we hypothesize:

H7 CNK is positively related to salesperson performance. 


\section{Research Method}

We collected data from car dealers in China using questionnaires. The reasons that we selected salespersons of car retailing business as our sample can be summed as follows. For one thing, salespersons not only interact with customers in a sales district, but also obtain help from their organizations. For another thing, customers often make rational decisions on buying cars, a salesperson needs to know what factors affected customers' decision-making. Based on these two reasons, we believe salespersons in car dealers are an optimal sample for our study.

The questionnaire used in this study was first developed in English and then translated into Chinese, and translated into English to ensure conceptual equivalence. According to the steps suggested by Brislin (1970) and Sekaran (1983), the back-translated English version was checked against the original English one. Some questions were reworded to better reflect the original meaning in English. Moreover, to guarantee the content and validity of measures in the context of China, we invited three professors in marketing and organizational behavior to evaluate questions in Chinese and conducted 10 in-depth interviews with senior marketing managers of car dealers, in which we asked them to verify the relevance and completeness of the questionnaire items. Based on their advice, we revised a few items to heighten the clarity of our questionnaire.

Modified questionnaires were delivered by mail from April to August in 2010. We investigated car dealers in Nanjing, Zhenjiang, Changzhou, Yangzhou and Suzhou. Samples were obtained by two ways. One was via the social network of our researchers, the other was via yellow pages in the chosen cities and relevant web sites. We sent 452 questionnaires to car dealers in the above cities. 245 were returned, including 212 valid ones (response rate $=46.9 \%$ ). The details of survey sample are shown in Table1.

With regard to the possibility of non-response bias, we assessed it by comparing the first and last waves of response. If data from early respondents did not show a statistically significant difference from that of late respondents, according to Armstrong and Overton (1977), the impact from non-response bias is not significant to the data. In our study, the first 50 and the last 50 questionnaires were selected as the first and last waves of response respectively. All questions were then conducted to examine the differences in the answers between the two waves of response by carrying out independent sample $t$-tests. The results showed that all significant values of $t$-tests performed were above 0.05 , demonstrating that results of the survey were unlikely to be significantly affected by the non-response bias. 
Table 1 Profile of The Survey Sample

\begin{tabular}{clrc}
\hline \multicolumn{1}{c}{ Characters } & Sum & Percent (\%) \\
\hline \multirow{3}{*}{ Education } & high school & 47 & 22.17 \\
& Bachelor degree & 149 & 70.28 \\
& Master degree & 16 & 7.55 \\
\hline \multirow{5}{*}{ City } & Nanjing & 53 & 25.00 \\
& Zhenjiang & 21 & 9.91 \\
& Changzhou & 33 & 15.57 \\
& Wuxi & 28 & 13.21 \\
& Yangzhou & 30 & 14.15 \\
& Suzhou & 47 & 22.17 \\
\hline \multirow{3}{*}{ Date of } & Less than 2 years & 58 & 27.35 \\
establishment & 2-5 years & 127 & 59.84 \\
& More than 5 years & 27 & 12.81 \\
\hline
\end{tabular}

\section{Measurement}

We obtained our questionnaire items largely from the extant literature. Questionnaire items of POS, guanxi and control variables were measured, using 7-point Likert-type scales in which "1" represented "strongly disagree" and "7" "strongly agree." As for personal performance, "1" represented "extremely bad" and "7" "extremely good."

We measured CNK according to Homburg et al.'s (2009) approach. Customers were asked to rank 6 buying needs according to their importance (security, fuel consumption, appearance, brand and service). Using dyadic difference scores, we operationalized CNK as the sum of the absolute differences between customer and employee rankings multiplied by -1 . Hence the highest value reflected the smallest discrepancy between actual and perceived customer needs (Homburg et al., 2009).

Measurement of POS was adopted from the research of Eisenberger et al. (1986) and Johlke et al. (2002), four items were selected to fit with the context of automobiles industry in China, including "my firm would not ignore the complaint from me," "my firm strongly considers my goals and values when making decisions," "my firm really cares about my well-being," "my firm cares about my opinions."

Measurement of guanxi was adopted from Lee and Dawes (2005), four items were used, including "both me and the customer care about mianzi," "when interacting with the customers, we care about each other," "if I helped the customer before, the customer will help me as a return," "I will feel embarrassed 
if I refuse requests from the customer."

Personal performance items were adopted from Ingram, Lee and Lucas (1991) and Behrman and Perreault (1982), we measured personal performance from the four perspectives, namely amount of sales, selling high-profit products, selling new products and contributions to seize the market share.

Control variables. We selected emotional labor, job know-how and environmental uncertainty as control variables. The items of emotional labor include "tried to actually experience the emotions I had to show to the customer," "I worked hard to feel the emotions that I needed to show to this customer," "I made a strong effort to actually feel the emotions that I needed to display toward this customer," "I just pretended to have the emotions I needed to display to this customer.," "I put on a 'mask' in order to display the emotions my manager wants me to display.," "I put on a 'show' or 'performance' when interacting with this customer." (Groth et al., 2009). As for job know-how, we listed the knowledge about car manufacturers, automotive intellectual property, structure of automobiles, car maintenance. The environmental uncertainty measure consisted of four items developed by Khandwalla (1976), namely perceived environment uncertainty can be very dynamic, very risky, very hostile, very rapidly expanding.

Table 2 displays the psychometric properties of the measures, and Table 3 provides the correlations of the framework variables. Cronbach's alpha, composite reliability (CR) and average variance extracted for all measurement scales demonstrate sufficient reliability and convergent validity. More

Table 2 Psychometric Properties of Measures

\begin{tabular}{ccccccc}
\hline Variables & Item & $\begin{array}{c}\text { Factor } \\
\text { loading }\end{array}$ & Cronbach's $\alpha$ & CR & AVE & VIF \\
\hline \multirow{2}{*}{ POS } & 1 & 0.93 & & & & \\
& 2 & 0.74 & 0.862 & 0.8682 & 0.628 & 3.5 \\
& 3 & 0.6 & & & & \\
\hline \multirow{3}{*}{ Guanxi } & 4 & 0.86 & & & & \\
& 5 & 0.79 & & & & \\
& 6 & 0.82 & 0.932 & 0.9077 & 0.7114 & 1.3 \\
& 7 & 0.89 & & & & \\
Personal & 8 & 0.87 & & & & \\
performance & 9 & 0.57 & & & & \\
& 10 & 0.71 & \multirow{2}{*}{0.846} & 0.8573 & 0.61 & \\
\hline
\end{tabular}


specifically, for all constructs, no coefficient alpha values and CR were lower than 0.70, which is the recommended threshold suggested by Bagozzi and Yi (1988) and average variance extracted was greater than 0.50 .

We tested the discriminant validity of measures using the criterion proposed by Fornell and Larcker (1981). The average variance extracted by each construct is greater than the square of the correlation between that construct and all other constructs in that measurement model (Fornell and larker, 1981). According to Table 2 and 3, the analysis suggests that we achieve discriminant validity among the constructs in our study.

To control for multicollinearity, we checked the variance inflation factors (VIF) of the variables. Except the VIF of POS (= 3.5), VIF of other variables in our study were 1.3 , all smaller than 5 , indicating that there was no multicollinearity problems (Kleinbaum et al., 1998).

Table 3 Descriptive Statistics and Pearson's Correlation Matrix

\begin{tabular}{lrrllll}
\hline \multicolumn{1}{c}{ Variables } & M & S.D. & \multicolumn{1}{c}{$\mathbf{1}$} & $\mathbf{2}$ & $\mathbf{3}$ & $\mathbf{4}$ \\
\hline Guanxi & 5.726 & 0.954 & 1.000 & & & \\
POS & 5.341 & 1.155 & $0.308^{* *}$ & 1.000 & & \\
CNK & -4.337 & 1.276 & $0.441^{* *}$ & $0.387^{* *}$ & 1.000 & \\
Personal Performance & 5.454 & 1.054 & $0.552^{* *}$ & $0.406^{* *}$ & $0.666^{* *}$ & 1.000 \\
\hline
\end{tabular}

Note: ** indicates $p<0.01$.

\section{Analysis and Results}

Table 3 reports the descriptive statistics and Pearson Correlation Coefficients for all constructs involved in this study. Hierarchical multivariate regression analysis was used to test the hypotheses mentioned above. The means of scores of each item were used to reflect its average situation.

\subsection{Direct Effect}

The direct effects in our models were checked. Based on M2, M3 and M4, it is obvious that $\operatorname{POS}(\beta=0.396, p<0.01 ; \beta=0.379, p<0.01)$ and guanxi $(\beta=$ $0.400, p<0.01 ; \beta=0.351, p<0.01$ ) have significantly positive impact on CNK: H1 and H4 were supported. M6, M7 and M9 showed that personal performance is significantly influenced by guanxi $(\beta=0.458, p<0.01 ; \beta=0.450, p<0.01)$ and $\operatorname{POS}(\beta=0.221, p<0.1 ; \beta=0.163, p<0.1)$, supporting $\mathrm{H} 2$ and $\mathrm{H} 5$. Similarly, as shown in M8 and M10, H7 was supported $(\beta=0.576, p<0.01 ; \beta=$ $0.489, p<0.01)$. 
Table 4 Hypotheses Testing: Hierarchical Multivariate Regression

\begin{tabular}{lcccc}
\hline \multicolumn{5}{c}{ Customer Needs Knowledge } \\
\hline Constant & M1 & M2 & M3 & M4 \\
Control variables & $-4.625^{* * *}$ & $-6.876^{* * *}$ & $-7.594^{* * * *}$ & $-9.385^{* * *}$ \\
Uncertainty & 0.056 & & & \\
Emotional labor & $-0.276^{* * *}$ & 0.044 & 0.049 & 0.046 \\
Job know-how & $0.122^{*}$ & $-0.203^{* * *}$ & 0.058 & 0.086 \\
\hline Independent & & -0.043 & 0.11 & -0.046 \\
variables & & & & \\
Guanxi & & $0.396^{* * *}$ & & $0.379^{* * *}$ \\
POS & $9.200^{* * *}$ & $15.830^{* * *}$ & $10.052^{* * *}$ & $0.351^{* * *}$ \\
\hline$F$ & $9.200^{* * *}$ & $31.654^{* * *}$ & $11.248^{* * *}$ & 29.984 \\
$\Delta F$ & 0.117 & 0.234 & 0.163 & 0.269 \\
$R^{2}$ & 0.104 & 0.219 & 0.146 & 0.251 \\
Adjusted $R^{2}$ & 0.117 & 0.117 & 0.046 & 0.106 \\
$\Delta R^{2}$ & & & \\
\hline Not: & & & & \\
\hline
\end{tabular}

Note: $*$ indicates $p<0.1, * *$ indicates $p<0.05, * * *$ indicates $p<0.01$.

Table 5 Hypotheses Testing: Hierarchical Multivariate Regression

\begin{tabular}{|c|c|c|c|c|c|c|}
\hline \multicolumn{7}{|c|}{ Personal performance } \\
\hline & M5 & M6 & M7 & M8 & M9 & M10 \\
\hline Constant & $4.760^{* * *}$ & $2.665^{* * *}$ & $3.402^{* * *}$ & $6.962^{* * *}$ & $1.644^{* * *}$ & $5.432^{* * *}$ \\
\hline \multicolumn{7}{|l|}{$\begin{array}{l}\text { Control } \\
\text { variable }\end{array}$} \\
\hline Uncertainty & $0.132^{* *}$ & $0.118^{* *}$ & $0.128^{* *}$ & $0.099^{* *}$ & $0.115^{*}$ & $0.096^{* *}$ \\
\hline Emotional labor & $-0.317^{* * *}$ & -0.232 & -0.132 & $-0.157^{* * *}$ & -0.098 & -0.14 \\
\hline Job know-how & $0.226^{* * *}$ & 0.035 & $0.219^{* *}$ & $0.156^{* * *}$ & 0.034 & 0.056 \\
\hline \multicolumn{7}{|l|}{$\begin{array}{l}\text { Independent } \\
\text { variable }\end{array}$} \\
\hline Guanxi & & $0.458^{* * *}$ & & & $0.450^{* * *}$ & $0.266^{* * *}$ \\
\hline POS & & & $0.221^{*}$ & & $0.163^{*}$ & -0.009 \\
\hline $\mathrm{CNK}$ & & & & $0.576^{* * *}$ & & $0.489^{* * * *}$ \\
\hline$F$ & $19.425^{* * *}$ & $31.178^{* * *}$ & $15.699^{* * *}$ & $54.332^{* * *}$ & $25.623^{* * *}$ & $43.117^{* * *}$ \\
\hline$\Delta F$ & 19.425 & 52.115 & 3.751 & 124.463 & 27.496 & 80.899 \\
\hline$R^{2}$ & 0.219 & 0.376 & 0.233 & 0.512 & 0.383 & 0.558 \\
\hline Adjusted $R^{2}$ & 0.208 & 0.364 & 0.218 & 0.503 & 0.368 & 0.545 \\
\hline$\Delta R^{2}$ & 0.219 & 0.157 & 0.014 & 0.293 & 0.165 & 0.174 \\
\hline
\end{tabular}

Note: * indicates $p<0.1$; ** indicates $p<0.05$; *** indicates $p<0.01$. 


\subsection{Mediating Effect}

This study followed Baron and Kenny's (1986) procedures to analyze the mediating effect of CNK between guanxi/POS and personal performance. The first step is to check whether there is a significant mediating effect between them. Results of Sobel test showed that the significant mediating effects exist in two paths (indicators were 4.018 and 2.956, respectively). As shown in M6 and M7, both guanxi and POS have significant impact on personal performance. After the introduction of CNK, guanxi remains significantly related to personal performance. However, the significant impact of POS on personal performance disappeared. Therefore, CNK plays a complete mediation role in the relationship between POS and personal performance, but the partial mediation of CNK appears in the effects of guanxi on personal performance.

Table 6 Summary of Hypotheses and Results

\begin{tabular}{ll}
\hline Hypotheses & Result \\
\hline H1: POS is positively related to the CNK of salesperson & Supported \\
H2: POS is positively related to salesperson performance & Supported \\
H3: CNK acts as a mediator between POS and salesperson & Supported \\
$\quad$ performance & (complete mediation) \\
H4: Guanxi is positively related to the CNK of salesperson & Supported \\
H5: Guanxi is positively related to salesperson performance & Supported \\
H6: CNK acts as a mediator for the relationship between Guanxi & Supported \\
and salesperson & (partial mediation) \\
H7: CNK is positively related to salesperson performance & Supported \\
\hline
\end{tabular}

\section{Conclusions and Implications}

Our findings shown in Table 6 provide implications for practitioners and researchers. First of all, with regard to POS, our study demonstrates that the higher the POS, the better the CNK salespersons can achieve. Moreover, salesperson performance can be enhanced by POS via the full mediation of CNK. These findings imply that in order to achieve better salespersons' outcomes, companies need to provide necessary support or training to help their salesperson develop necessary ability to identify accurately customers' need.

Secondly, our study found that guanxi acts as a bridge between salespersons and customers. It can significantly increase employees' CNK and performance. These results suggest that companies should encourage its sales force to develop guanxi with customers. Meanwhile, salespersons should be aware of the importance of good guanxi with customers. In building up good guanxi, 
salespersons should learn how to recognize customers' needs.

Lastly, the finding that employees' CNK facilitates their performance demonstrates the importance of market orientation, and indicates that salesperson needs to give priority to identifying customer needs accurately.

\section{Limitations and Suggestions for Further Research}

This study has several limitations that provide potential avenues for further research. First, the sample was exclusively from salespersons in the automobile industry. This might have affected the generalization of some of our findings. Our constructs need to be tested in other industries in the future. Second, in this paper, we only focus on direct and mediation effects. There might be moderating variables which can influence our model. Future studies should examine the impacts of moderating variables.

Acknowledgements This work is supported by the National Natural Science Foundation of China (No. 70902009) and the China Direct Selling Research Center at Nanjing University.

\section{References}

Abramson, M. R, \& Ai, J. X. 1997. Using guanxi-style buyer-seller relationships in China: Reducing uncertainty and improving performance outcomes. The International Executive, 39(6): 765-804.

Allen, D. G., Shore, L. M., \& Griffeth, R. W. 2003. The role of perceived organizational support and supportive human resource practices in the turnover process. Journal of Management, 29(1): 99-118.

Armstrong, J. S., \& Overton, T. S. 1977. Estimating non-response bias in mail surveys. Journal of Marketing Research, 14(3): 396-402.

Bagozzi, R. P., \& Yi, Y. 1988. On the evaluation of structural equation models. Journal of the Academy of Marketing Science, 16(1):74-94.

Baron, R. M., \& Kenny, D. A. 1986. The moderator-mediator variable distinction in social psychological research: Conceptual, strategic, and statistical considerations. Journal of Personality and Social Psychology, 51(6): 1173-1182.

Behrman, D. N., \& Perreault, W. D. 1982. Measuring the performance of industrial salespersons. Journal of Business Research, 10(3): 355-370.

Bell, S. J., \& Menguc, B. 2002. The employee-organization relationship, organizational citizenship behaviors, and superior service quality. Journal of Retailing, 78(2): 131-146.

Bishop, J. W., Scott, D. K., \& Goldsby, M. G. 2005. A construct validity study of commitment and perceived support variables: A multifunction approach across different team environments. Group \& Organization Management, 30(2): 153-180.

Bitner, M. J., Brown, S. W., \& Meuter, M. L. 2000. Technology infusion in service encounters. Journal of the Academy of Marketing Science, 28(1): 138-149.

Blau, P. 1964. Exchange and power in social life. New York: Wiley.

Brislin, R. W. 1970. Back-translation for cross-cultural research. Journal of Cross-Cultural Psychology, 1(3): 185-216. 
Chen, X. P. \& Chen, C. C. 2004. On the intricacies of the Chinese guanxi: A process model of guanxi development. Asia Pacific Journal of Management, 21(3): 305-324.

Chong, H., White, R. E., \& Prybutok, V. 2001. Relationship among organizational support, JIT implementation, and performance. Industrial Management \& Data Systems, 101(6): 273-281.

Davies, H. 1995. Interpreting guanxi: The role of personal connections in a high context transitional economy. In H. Davies (Ed.), China business: Context and issues. Hong Kong: Longman.

Eisenberger, R., Fasolo, P., \& Davis-LaMastro, V. 1990. Perceived organizational support and employee diligence, commitment and innovation. Journal of Applied Psychology, 75(1): $51-59$.

Eisenberger, R., Huntington, R., Hutchison, S., \& Sowa, D. 1986. Perceived organizational support. Journal of Applied Psychology, 71(3): 500-507.

Fornell, C., \& Larcker, D. F. 1981. Evaluating structural equation models with unobservable variables and measurement error. Journal of Marketing Research, 18(1): 39-50.

Geddie, M. W., DeFranco, A. L., \& Geddie, M. F . 2002. From guanxi to customer relationship marketing: How the constructs of guanxi can strengthen CRM in the hospitality industry. Journal of Travel \& Tourism Marketing, 13(3):19-33.

George, W. R. 1990. Internal marketing and organizational behavior: A partnership in developing customer-conscious employees at every level. Journal of Business Research, 20(1): 63-70.

Goff, B. G., Boles, J. S., Bellenger, D. N. \& Stojack, C. 1997. The influence of salesperson selling behaviors on customer satisfaction with products. Journal of Retailing, 73(2): 171-183.

Groth, M., Hennig-Thurau, T., \& Walsh, G. 2009. Customer reactions to emotional labor: The roles of employee acting strategy and customer detection accuracy. Academy of Management Journal, 52(5): 958-974.

Gwinner, D. G., Gremler, D. D., \& Bitner, M. J. 1998. Relational benefits in services industries: The customer's perspective. Journal of the Academy of Marketing Science, 26(2): 101-114.

Gwinner, K. P., Bitner M. J., Brown, S. W., \& Kumar, A. 2005. Service customization through employee adaptiveness. Journal of Service Research, 8(2): 131-148.

Hochwarter, W., Kacmar, C., \& Perrewe, P., \& Johnson, D. 2003. Perceived organizational support as a mediator of the relationship between politics perceptions and work outcomes. Journal of Vocational Behavior, 63(3): 438-456.

Homburg, C., Wieseke, J., \& Bornemann, T. 2009. Implementing the marketing concept at the employee-customer interface: The role of customer need knowledge. Journal of Marketing, 73(4): 64-81.

Ingram, T., Lee, K. S., \& Lucas, G. H. 1991. Commitment and involvement: Assessing a salesforce typology. Journal of the Academy of Marketing Science, 19(3): 187-197.

Johlke, M. C., Stampe, C. L., \& Shoemaker, M. E. 2002. Antecedents to boundary-spanner perceived organizational support. Journal of Managerial Psychology, 17(2): 116-128.

Kleinbaum, D. G., Lawrence L. K., Muller, K. E. \& Nizam, A. 1998. Applied regression analysis and other multivariate methods. Pacific Grove, CA: Duxbury Press.

Kohli, A. K., \& Jaworski, B. J. 1990. Market orientation: The construct, research propositions, and managerial implications. Journal of Marketing, 54: 1-18.

Khandwalla, P.N. 1976. The design of organizations, harcourt brace Jovanovich. New York, NY.

Kraimer, M. L., Wayne, S. J., \& Jaworski, R. A. 2001. Sources of support and expatriate performance: The mediating role of expatriate adjustment. Personnel Psychology, 54(1): 
71-99.

Lee, D. Y., \& Dawes, P. L. 2005. Guanxi, trust, and long-term orientation in Chinese business markets. Journal of International Marketing, 13(2): 28-56.

Levinson, H. 1965. Reciprocation: the relationship between man and organization. Administrative Science Quarterly, 9(4): 370-390.

Liao, H., \& Chuang, A. 2004. A multilevel investigation of factors influencing employee service performance and customer outcomes. Academy of Management Journal, 47(1): $41-58$.

Luo, Y., \& Chen, M. 1997. Does guanxi influence firm performance? Asia Pacific Journal of Management, 14(1): 1-16.

Luo, Y., \& Peng, M. W. 1999. Learning to compete in a transition economy: Experience, environment, and performance. Journal of International Business Studies, 30(2): 269-295.

Moorman, R. H., Blakely, G. L., \& Niehoff, B. P. 1998. Does perceived organizational support mediate the relationship between procedural justice and organizational citizenship behavior? Academy of Management Journal, 41(3): 351-357.

Morrison, E. W. 1996. Organizational citizenship behavior as a critical link between HRM practices and service quality. Human Resource Management, 35(4): 493-512.

Pettijohn, C. E., Pettijohn L. S., \& Taylor, A. J. 2002. The influence of salesperson skill, motivation, and training on the practice of customer-oriented selling. Psychology and Marketing, 19(9): 743-757.

Ramasamy, B., Goh, K. W., \& Yeung, M. C. H. 2006. Is guanxi (relationship) a bridge to knowledge transfer? Journal of Business Research, 59(1): 130-139.

Sekaran, U. 1983. Methodological and theoretical issues and advancements in cross-cultural research. Journal of International Business Studies, 14(2): 61-73.

Sharma, A., \& Lambert, D. M. 1994. How accurate are salespersons' perceptions of their customers? Industrial Marketing Management, 23(4): 357-365.

Sinkula, J. M. 1994. Market information processing and organizational learning. Journal of Marketing, 58(1): 35-45.

Stamper, C. L., \& Johlke, M. C. 2003. The impact of perceived organizational support on the relationship between boundary spanner role stress and work outcomes. Journal of Management, 29(4): 569-588.

Stinglhamber, F., \& Vandenberghe, C. 2003. Organizations and supervisors as sources of support and targets of commitment: A longitudinal study. Journal of Organizational Behavior, 24(3): 251-270.

Wang, C. L. 2007. Guanxi vs. Relationship marketing: Exploring underlying differences. Industrial Marketing Management, 36(1): 81-86.

Wayne, S. J., Shore, L. M., \& Liden, R. C. 1997. Perceived organizational support and leader-member exchange: A Social exchange perspective. Academy Of Management Journal, 40(1): 82-111.

Wong, A., \& Tjosvold, V. 2010. Guanxi and conflict management for effective partnering with competitors in China. British Journal of Management, 21(3): 772-788.

Zeithaml, V., \& Bitner, M. 1996. Services marketing. Singapore: McGraw-Hill. 